\title{
Critical Appraisal of Web-Based Passenger Information Systems
}

\author{
Gaurav V. Jain
}

Indian Institute of Technology Roorkee and Space Applications Centre

\author{
S. S. Jain, Manoranjan Parida \\ Indian Institute of Technology Roorkee
}

\begin{abstract}
Passenger information is vital for developing a user-friendly public transportation system. Websites are rapidly gaining popularity for public transport information dissemination, particularly due to their anytime-anywhere availability and their suitability for the multimodal applications and multilingual interface. Internet-based Passenger Information Systems (PIS), therefore, have become common in developed countries. The development of PIS for urban transport in India however, is at an experimental stage with very few operational deployments. This paper attempts to examine the current state-of-the-art features in Web-based passenger information systems in India and abroad, while critically evaluating the existing sources of public transport information in Ahmedabad as a case study. Ahmedabad, like several other Indian cities, has fixed-route regular bus services in conjunction with a recently-introduced bus rapid transit (BRT) system. The study compares the information content in printed transit timetables, Google Transit, and websites of the transit agencies, with the spatial dataset of public transport network prepared by integrating information from several sources. The results highlight the issues pertaining to accuracy, coverage, and timeliness of information contents available in developing countries, requiring innovative technological interventions to meet the growing information needs of commuters.
\end{abstract}

\section{Introduction}

Public transport information systems form an integral part of any modern public transport deployment. Relevant information is vital for developing a user-friendly public transportation system (O'Flaherty 1997), and its availability may profoundly influence the use of public transport (lles 2005). An effective public transport information system may enable potential users to plan multimodal journeys, minimize wait times at stations, and increase overall satisfaction with the service. 
The information regarding the schedules and routes of public transport services is mostly fragmented and scattered across various sources (Zografos et al. 2009), which not only inconveniences the transit users but also discourages modal shift from private to public transport modes. Printed transit timetables, occasionally with network maps, are published by public transport operators and are the most commonly-available form of information at the disposal of transit users. However, difficulty in understanding such timetables, due to very large information content, limited circulation, and slow process of updates, have become a barrier in the use of such information (Bae 1995). Cain (2007) investigated the extent to which the lack of ability to use printed transit information materials correctly for trip planning may be a hindrance to transit use. The study concluded that only 52.5 percent of transit users were able to plan their journeys correctly using printed information. The problem is further compounded when multimodal trips are to be planned (Caulfield 2007; Tam and Lam 2005).

Telematics-based public transport information systems, therefore, may complement the conventional media, such as timetables and network maps, by providing reliable and near real-time data. Websites are rapidly gaining popularity among passengers, particularly due to their anytime-anywhere availability and their suitability for multimodal applications and multilingual interface. Web-based Passenger Information Systems (PIS) are userfriendly, easily accessible, and timely and have proved to be advantageous in both pre-trip and en-route information (Infopolis Consortium Inc. 1998; TRB 2003b).

India's National Urban Transport Policy (Ministry of Urban Development 2006) contemplates the establishment of a multimodal public transport system providing seamless travel across different modes in Indian cities. To combat the conventional "service for the poor" image, the policy has placed significant emphasis on modernization of urban transport infrastructure, improved passenger information systems, and use of intelligent transport systems for monitoring and control, apart from several other recommendations. The last decade alone witnessed introduction of bus rapid transit (BRT) systems, complementing the existing regular bus services in several Indian cities. A PIS has been identified as an important component of a range of Intelligent Transport Systems (ITS) contemplated as part of BRT projects, and thereby in-terminal and on-board PIS have been deployed. However, given the increasing requirement for multimodal travel, Webbased PIS also have become essential.

This paper attempts to review the current state-of-the-art features in Web-based PIS in India and abroad, while critically evaluating existing sources of public transport information in Ahmedabad city of Gujarat as a case study. The second section reviews studies on design and development of Web-based PIS, mostly in developed countries, along with the studies intended for evaluating such PIS implementations. The third section elaborates on experimental as well as operational PIS in India, and the fourth section identifies and critically examines various sources of public transport information in Ahmedabad. The final section presents conclusions and identifies issues to be addressed in Indian cities for an effective Web-based PIS. 


\section{Web-Based PIS: Global Scenario}

Casey et al. (2000) identified three categories of transit information, each with a unique set of information and different preferred modes of information dissemination: (1) pretrip information, (2) in-terminal or way-side information, and (3) on-board information. Pre-trip information, which includes general service information, itinerary planning, realtime information, and multimodal traveler information, is required prior to commencement of the journey. Caulfield (2007) concludes that websites are found to be particularly useful for meeting information requirements at the pre-trip planning stage.

The integration of transit information with spatial information has benefited immensely from the developments in Internet Geographical Information Systems (GIS). Peng and Huang (2000) discussed the taxonomy of Web-based transit information systems and observed that most transit websites provided Web-browsing and text-search capabilities with static graphic links to transit networks but lacked Internet GIS capabilities. They proposed a three-tier architecture comprising a Web browser, a Web server, and an application server composed of a map server, a network analysis server, and a database server. The proposed transit information system based on Internet-GIS with an interactive map interface provided information on transit routes, schedules, and trip itinerary planning. Cherry et al. (2006) emphasized the need for map-based input of trip origin and destination in transit trip planners apart from manually entering the text and selecting a landmark from a drop-down box. They developed a prototype of an itinerary planner using an ArclMS for the Sun Tran bus network in Tucson, Arizona, with an interactive map to point and click on a location for the origin and destination. Gou (2011) confirmed that a schematic transit map indeed affects the path choices of transit users in London Underground subway.

Web-based PIS have been found advantageous in situations where multiple modes and multiple agencies are involved. Zografos and Androutsopoulos (2008) proposed a multimodal PIS called ENOSIS for urban and interurban trips, particularly to provide information on intermediate transfers between systems with different modes and geographic coverage. It provided an interface to external information systems for receiving real-time alerts from transit service providers, which are communicated to users by the Travel Life Cycle Manager (TLCM) that tracks a trip during its life cycle for a given trip itinerary. The primary issue involving multimodal transport information is the involvement of multiple agencies. Jung et al. (2001) proposed architecture for an Intelligent Transport Support System (ITSS) for acquisition, integration, and dissemination of information over the Internet from multiple information sources. Wang and Kampke (2006) emphasized the need for a decentralized traveler information system ensuring privacy and control on the data held by multiple transit service providers. Peng and Kim (2008) addressed the problems encountered by commuters when the journey involves more than one transit agency, which causes problems involving interoperability and data exchange across transit agencies. They proposed XML-based Advanced Traveler Information System (ATIS) standards for data exchange across multiple agencies. The system, however, requires commitment of transit service providers in implementing such standards while designing PIS.

Transit information can be of a static nature, such as route maps, schedules, and fares, which are updated only once in a while, or it may be dynamic, such as route delays and 
real-time arrival estimates that are continuously updated (Casey et al. 2000). In recent years, the incorporation of Automatic Vehicle Location (AVL) technologies in public transport systems has resulted in an increase in real-time passenger information systems. The Transportation Research Board (2003a) notes that 88 transit agencies in the United States had operational AVL systems, and 142 were planning such systems by the end of year 2000. GPS has emerged as a common positioning technology owing to low infrastructure cost, easy deployment, and reasonably high level of accuracy. Although real-time passenger information is largely offered at wayside or in-terminal stages, transit websites are increasingly being used for the purpose. Peng and Huang (2000) conceptualized an interface for displaying bus locations using AVL data. Hiinnikainen et al. (2001) proposed architecture for a PIS for public transport services, which, in addition to other features, also incorporated real-time information dissemination to the personal mobile terminals using the telecommunication network. TRB (2003a) provided an exhaustive review of various aspects of real-time bus arrival information systems, including case studies of Regional Transportation District, Denver; King County Metro, Seattle; TriCounty Metropolitan Transportation District of Oregon, Portland; San Luis Obispo Transit; Acadia National Park-Island Explorer Bus System; and London Bus Services Limited. Websites are also useful in providing additional information necessary for making the trip, fulfilling the very purpose for which the trips are made. Watkins et al. (2010) developed a search tool for local restaurants, shopping, parks and other amenities based on transit availability from the user's origin. Farag and Lyons (2012) agree that public transport information should be marketed simultaneously with public transport use.

The proliferation of Web-based PIS in several cities across the globe has enthused researchers in evaluating the performance of such deployments. Quantification of the benefits of Web-based PIS, such as an increase in transit ridership and improvement in user ability to use transit systems, is difficult, and often subjective. Eriksson et al. (2007) developed an evaluation tool based on an E-S-QUAL scale to assess the quality of public transport information on the Internet. The study analysed 58 responses to a questionnaire to quantify the quality of websites. Grotenhuis et al. (2007) studied the quality of integrated multimodal travel information in public transport and its role in time and effort savings of the customers. Politis et al. (2010) evaluated real-time bus passenger information system from the user point of view in Thessaloniki, Greece. Cheng (2011) investigated passenger perceptions of electronic service quality (e-SQ) delivery through the Taiwan High Speed Rail's (THSR) website to examine the quality of transportation information as well as website services.

Websites have become a common medium of information dissemination for transit agencies in developed countries, resulting in a large number of operational Web-based transit information systems. The Infopolis-2 (1998) project prepared an inventory of more than 300 websites of public transit service providers in Europe, covering different modes such as rail, bus, metro, tram, ferry, and coach, and with varying functionalities. It further adds that out of 27 websites that responded to their survey, nine supported more than three transit modes. Casey (1999) identified that 163 transit agencies in the U.S. that already had or planned to implement an automated traveler information system. Radin et al. (2002) investigated transit trip planners provided by 30 public transport service providers 
in the U.S., detailing the inputs, outputs, and advanced features such as multimodal and multilingual support, offered by these agencies.

Transport Direct, a multimodal journey planner for Britain (England, Wales, and Scotland), which became operational in December 2004, offers national journey planning across all modes (Maher 2008). The journey plans returned by Transport Direct are actually composite plans formed via queries to several different regional journey planners, some of which are created and maintained by third-party organizations. Journey plan responses are received in form of JourneyWeb XML standard, an XML protocol allowing the exchange of journey planning queries and answers (DfT 2013). Traveline Travel Services (2010) in the UK, BayernInfo (2013) in Germany, Kings Metro Transit Service (King County 2013) in Seattle, Bay Area Rapid Transit (San Francisco Bay Area Rapid Transport District 2013), and 511 (Metropolitan Transportation Commission 2013) in the San Francisco Bay Area are few other successful deployments of Web-based PIS. In recent years, Google Transit (Google Maps-Transit 2013), supported by its very-high-resolution satellite imagery and cartographic-quality maps (Google Maps 2013), has become the de facto choice in providing transit information. As of December 2012, more than 500 cities all over the world have adopted Google Transit (Google Maps-Transit 2013).

Web-based PIS have evolved over the past decade with the integration of Internet GIS (Peng and Huang, 2000; Cherry et al. 2006) to multimodal (Zografos and Androutsopoulos 2008) and multiagency systems (Wang and Kampke 2006, Peng and Kim 2008). The information content also has advanced from simple static information to real-time information (Peng and Huang 2000, Hiinnikainen et al 2001) and further integration with information regarding the purpose of trip (Watkins et al. 2010). MacDonald et al. (2006) claim that despite tremendous growth in traffic and traveler information services in the past decade, issues pertaining to information accuracy and reliability, multimodal support, timeliness of information, delivery of information, and service continuity across national borders present opportunities for future research in Europe. Similar concerns were raised by the Transportation Research Board (TRB 2003b) for transit information systems in the U.S. The quality of data used by traveler information systems needs to be improved with respect to level of detail, coverage, accuracy, and maintenance. Traveler information from multiple sources, including information on traffic and travel time, needs to be integrated, with the aim of providing more customer-focused and personalized information along with the real-time information.

\section{PIS in India}

The development of PIS for urban transport in India is at an experimental stage with very few operational deployments, as discussed herein.

\section{Experimental Systems}

Reddy (2002) developed an intelligent transport system in a GIS environment and proposed an ATIS for Hyderabad. The system was developed on ESRI's ArcView software and provided detailed transport- and tourist-related information. Ballaji et al. (2003) proposed a public transport information system for Chennai city using ESRI's ArcView software. Yoganand (2004) proposed a multimodal ATIS for Delhi Metro using ESRI's MapControl 
in Visual Basic. The application provided information about transport facilities in Delhi in addition to enabling the shortest path computation between given locations based on road length. A Web-based system was also developed using HTML and JavaScript with basic features such as pan, zoom, identify, and attribute search. Singh (2007) proposed a three-tier client-server architecture for an ATIS for developing countries for pre-trip information dissemination and also proposed design guidelines pertaining to organization and management of data used for information dissemination. Kasturia and Verma (2010) developed a multi-objective transit PIS for the regular bus service in Thane city using TransCAD.

\section{Operational Systems}

PIS has been planned as a part of BRT projects in several cities in India. Delhi deployed a Web-based PIS, developed by Delhi Integrated Multi Modal Transit System Ltd. (DIMTS 2010), which enabled passengers to track buses (both AC and non-AC) on BRT routes in Delhi. It provided route-wise expected arrival time of buses while displaying the location of buses on Google Maps. In Bangalore, the private firm MapUnity (2013) developed a traffic information system in collaboration with Bangalore Traffic Police and a private mobile service provider. It has also developed Urban Transport Information Systems for a number of other Indian cities, such as Bangalore, Chennai, Hyderabad, and Delhi. This system uses several types of input, such as teledensity data from a mobile telecom tower network, video images from police cameras, and location-tracking of buses and taxis, to create real-time knowledge of traffic conditions in the cities. These are made available through the mobile telecom network to city residents and are also accessible online. The website also offers determination of route between user-specified origin and destination stations for regular bus services.

Google Transit (2013) has identified nine Indian cities-Delhi, Bangalore, Hyderabad, Mumbai, Chennai, Ahmedabad, Pune, Kolkata, and Thane-to publish transit information online providing transit routes between an origin-destination pair. In a similar initiative, the Indian Bus Route Mapping Project (2013) has developed a transit trip planner for Chennai city using map data from OpenStreetMaps and a collaborative effort in mapping public transport network of the city. The efforts in development of Web-based PIS have gained momentum in Indian cities in recent years. The information content in such websites, however, presents challenges pertaining to reliability and completeness, which needs to be reviewed to improve customer acceptance.

\section{Public Transport Information in Ahmedabad}

To assess the quality of passenger information available in Indian cities, Ahmedabad has been selected as a case study for detailed analysis. The city is the fifth largest city in India, as per Census of India 2011, and operates regular fixed-route bus service in conjunction with BRT service, thereby representing the public transportation systems of most of the metropolitan cities in India. The BRT service in Ahmedabad has been widely acclaimed in India and abroad (AMC 2013) and is being considered as a model for other Indian cities as well. Furthermore, as the city is also covered by Google Transit, Ahmedabad offers the most appropriate case study for analyzing the quality of passenger information in Indian cities. 
Ahmedabad is the largest city of the state of Gujarat, located in the western part of India. The population of Ahmedabad Municipal Corporation, which was 3,520,085 in 2001, has already surpassed the 50 million mark, per provisional estimates released by Census of India 2011. The city is an established manufacturing hub and a center of trade and commerce. The public transport demand of the city is serviced by regular fixed-route bus services operated by Ahmedabad Municipal Transport Service (AMTS) and BRT service operated by Ahmedabad Janmarg Ltd. (AJL). AMTS operates more than 150 routes in Ahmedabad, covering nearly $500 \mathrm{~km}$ road length. BRT, which was introduced in the city in December 2009, is currently operational on 10 lines, with more than 100 BRT stops.

The public transit information in Ahmedabad is fragmented and scattered, which inconveniences transit users in planning multimodal journeys. The information regarding AMTS can be obtained from printed transit timetables and Google Transit. The printed transit timetables published by AMTS provide general service information, including a list of routes and major stops and a schedule of departure from origin stop. An updated list of routes and a text-based transit trip planner have also been provided on the website (AMTS 2013). Transit timetables are published in the native language, Gujarati. Google Transit, on the other hand, provides a map-based itinerary planner for AMTS-operated bus service. The information source for BRT is primarily its website (AMC 2013) and the in-terminal passenger information system. The website provides general service information, including routes, timetables, and stops, and the terminals provide transit network maps and real-time information on bus arrivals.

The quality of information with respect to level of detail, coverage, accuracy, and maintenance has been recognized as an important aspect for the success of Web-based PIS (TRB 2003b). To assess the quality of spatial and non-spatial contents of existing sources of information, a reference set of data was first prepared. The road network of Ahmedabad was mapped at 1:10,000 scale using Indian remote sensing data acquired by a Cartosat-1 PAN sensor fused with IRS P6 LISS-IV multispectral data. The spatial data of the bus stops of AMTS were created by integrating information from multiple sources such as printed timetables, Google Maps, published city atlases and guide-maps, and GPS. The bus routes were mapped based on the sequence of stops listed in the printed timetable of AMTS, and BRT stop locations were obtained from the website of Ahmedabad BRT and handheld GPS. Thus, a reference transport network dataset of the study area comprising all roads as links and the end-points of such links as nodes, including the stops of AMTS and BRT, was prepared for the assessment of quality of passenger transport information in Ahmedabad.

\section{AMTS Printed Transit Timetables}

The printed transit timetables published by AMTS include 1,025 bus stops out of the 1,533 bus stops identified and mapped on the reference transport network of the study area. The stops were compared with the actual number of bus stops marked on the reference transport network. It was observed that only 40 percent of the bus stops were listed in any given route, thereby providing incomplete transit information to the users, as shown in Figure 1. It is evident that as many as 50 percent of the bus routes have more than 50 bus stops. Incorporation of all bus stops in printed timetables along with their 
Plot of actual number of AMTS bus stops vs. number of AMTS bus stops listed in timetable

corresponding schedules will result in large booklets, which will not be handy for customers. Moreover, the production costs of such large timetables will rise, thereby making them unviable for distribution at the nominal fees being charged at present.

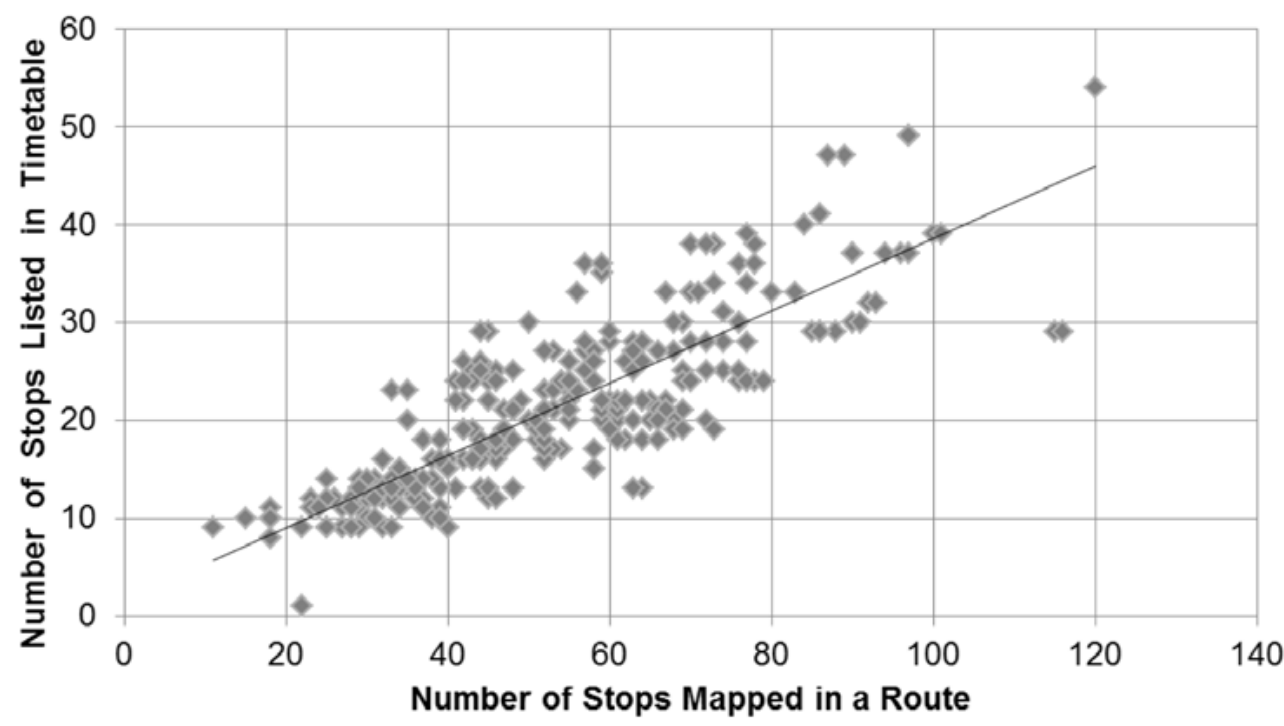

The inclusion of only selected bus stops may prove to be hindrance to trip planning if commuters are not aware of the bus route number beforehand. The difference in the number of routes passing through a given bus stop according to the information content of AMTS timetable and that of the reference database is shown in Figure 2. According to the AMTS timetable, only 9 bus stops are connected by more than 50 routes, while the database identifies 35 such stops. Similar observations can be made for bus stops connected by $5-10$ routes, $11-20$ routes, $21-30$ routes, and $31-50$ routes.

FIGURE 2.

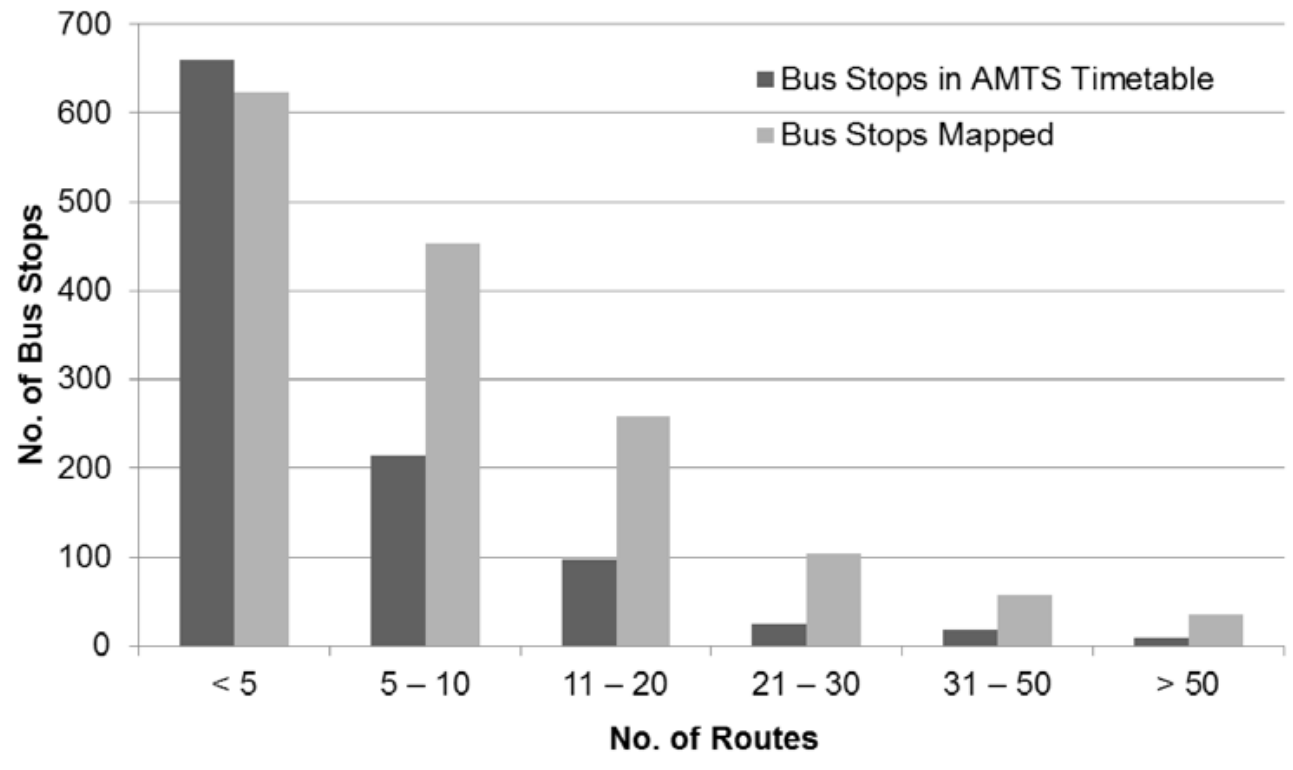

Number of routes passing through AMTS bus stops 
To understand the update frequency of the route structure in the transit timetables, routes listed in the 2010 ATMS timetable were compared with the undated AMTS bus route status from the ATMS website. The total number of routes listed in the AMTS timetable was 189 (including shuttle routes); the number of routes in March 2012 (from the ATMS website) was 171. This does not necessarily indicate the restructuring of AMTS routes, but rather hints at changes in information content over the period, as the ATMS timetable does not list shuttle routes. It was further observed that 26 routes had undergone changes in terms of route origin or destination, 16 routes from the AMTS timetables were not included in the 2012 route information, and 35 new routes were found in the AMTS route information.

\section{AMTS Information on the Internet}

Google Transit offers a transit trip planner for AMTS-operated regular bus service in Ahmedabad. The trip planner allows users to minimize either the journey time, the walk distance, or the transfers. The origin and destination points of the itinerary can either be located on a map or can be searched from the place-tags marked by Google Map users. The path returned is displayed graphically as a line diagram and is also plotted on the map. The path information comprises the name and location of the nearest boarding and alighting bus stops, the bus route(s) name and geometry as plotted on the map, and walk connections from trip origin and destination points to the respective nearest bus stops.

The quality of information content of Google Transit's trip planner depends primarily on its database of bus stops, bus routes, and timetable. To evaluate the bus stop information in Google Transit, 10 percent of bus stops (156) were randomly selected from the reference transport network of Ahmedabad, ensuring unbiased geographical coverage. These bus stops were searched in Google Transit, first using a map-based search and then a text-based search.

The map-based search using Google Transit was able to locate 98 bus stops out of the 156 initially sampled. An additional 58 stops were selected near the locations where Google Transit stops could not be identified, thereby increasing the sample size to 156 stops on Google Transit and a total of 214 stops in the reference database. The sample of bus stops thus selected included 165 stops identified in AMTS timetable, 25 stops obtained from Google Transit, and 27 stops from published city atlases. It was observed that the names of only 22 percent of the total stops in the sample perfectly matched the names in Google Transit, including 36 stops from the AMTS timetable and 11 stops from Google Transit. The difference in the number of stops mapped using Google Transit (25) and the number of stops with matching names (11) is due to corrections made to names incorporated based upon knowledge of local language and ancillary data at the time of database creation.

The dissimilarity in the names of bus stops from multiple sources was quantified using Jaro-Winkler distance and Levenshtein distance. The Jaro-Winkler distance metric is used to measure string similarity and is particularly advantageous for detecting typographical errors in short strings such as names. Levenshtein's distance, on the other hand, measures the difference in the sequence and determines the number of single-character edits required to change one word into another. The lower the value of these metrics, the lower is the similarity between strings being compared. The results of string similarity, as shown 
in Figure 3, indicates that nearly 48 percent of stop names have a similarity score greater than 95 percent on Jaro-Winkler similarity, and 33 percent have a Levenshtein distance above 95 percent, which implies that not only conventional key-word based searches are liable to fail but also that significant effort will be necessary to rectify the errors in the database. The dissimilarities in names are due to not only typographical errors but, in several instances, semantic issues arising on account of language; for example, in Table 1, the term "temple" may be written as "mandir" in Hindi and Gujarati, giving rise to two different names, "ISKCON Temple and "ISKCON Mandir," both referring to the same place.

FIGURE 3.

String comparison of bus stop names

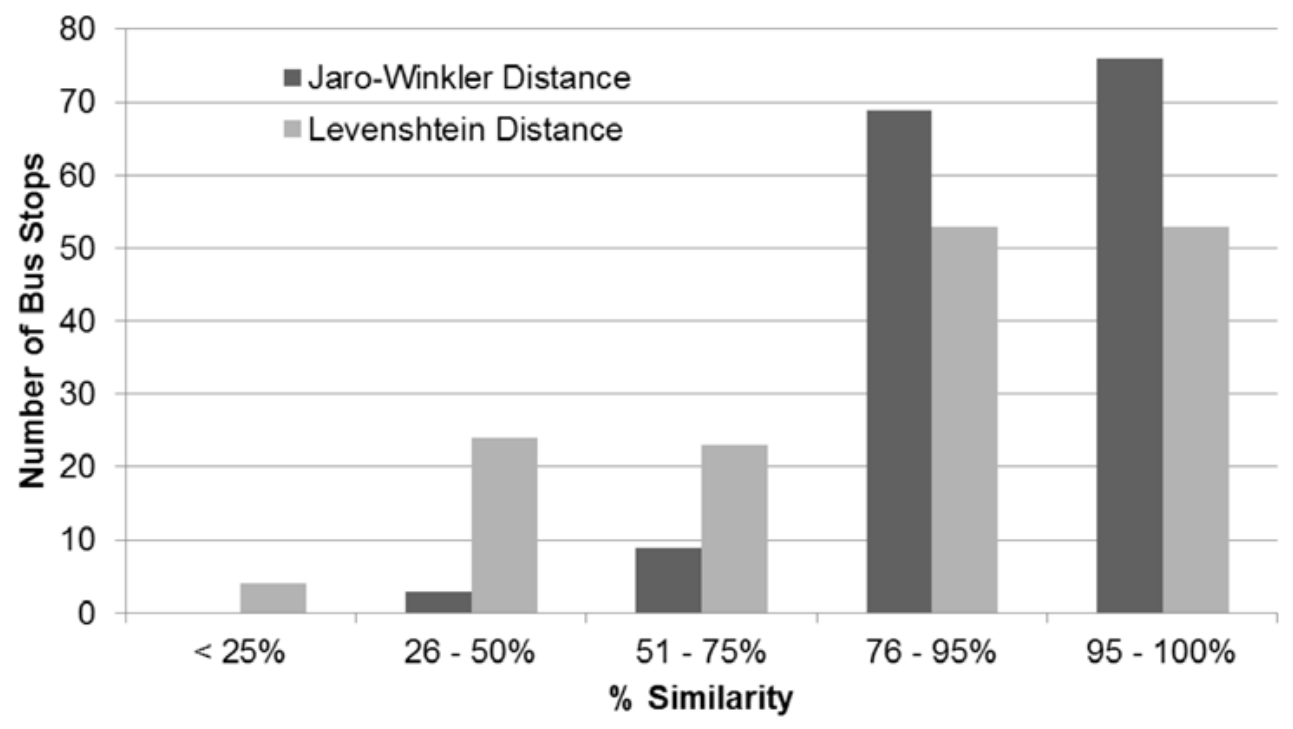

The text-based search was evaluated on the basis of the sample of 214 bus stops selected from reference transport network. The name of every bus stop mentioned in the reference transport database and its name in Google Transit obtained in a map-based search was entered as the origin in Google Transit's trip planner, and Lal Darwaja Bus Terminus, which is the largest bus terminal of Ahmedabad with the highest accessibility, was marked as the destination. The directions between the pair of origin and destination locations using public transport modes was computed to minimize the walking distance, which ensured that the nearest stop to the selected place-tag was located. The best path minimizing walk distance returned for each bus stop was tabulated according to the format shown in Table 1. The Node-ID (column 1) and Reference Node Name (column 2) were obtained from the reference database, the Google Transit Name (column 3) was obtained from the map-based search, and the remaining information in columns 4-9 was retrieved through the text-based search. In the example shown in the table, Node IDs 836, 2621, and 3454 indicate the correct identification of stops in both the map-based and the text-based searches, but route $44 / 3$ for node 2621 does not exist. Nodes 278, 6148, and 6412 were identified only in the map-based searches but could not be located in the textbased searches. Node 6928 was located in the text-based search but returned a different stop than the desired stop. Nodes 6538 and 7425 could not be detected in either the text-based search or the map-based search. Node 7425 is connected by an out-city route, which appears to be outside the coverage area of Google Transit. 


\section{TABLE 1.}

Evaluation Format for Keyword-based Search using Google Transit

\begin{tabular}{|c|c|c|c|c|c|c|c|c|}
\hline $\begin{array}{l}\text { Node } \\
\text { ID }\end{array}$ & $\begin{array}{l}\text { Reference } \\
\text { Node Name }\end{array}$ & $\begin{array}{l}\text { Google Transit } \\
\text { Name }\end{array}$ & $\begin{array}{l}\text { No. of } \\
\text { Tags }\end{array}$ & Closest Place- Tag Name & $\begin{array}{c}\text { Bus Stop } \\
\text { Nearest to } \\
\text { Tag }\end{array}$ & $\begin{array}{c}\text { Distance } \\
\text { from Tag to } \\
\text { Stop (m) }\end{array}$ & $\begin{array}{c}\text { Route } \\
\text { \# to Lal } \\
\text { Darwaja }\end{array}$ & $\begin{array}{l}\text { Travel } \\
\text { Time } \\
\text { (min) }\end{array}$ \\
\hline 836 & $\begin{array}{l}\text { Iskcon } \\
\text { Temple }\end{array}$ & ISKCON Mandir & 1 & $\begin{array}{l}\text { ISKCON Temple, Satellite, } \\
\text { Ahmedabad, Gujarat } 380059\end{array}$ & $\begin{array}{l}\text { ISKCON } \\
\text { Mandir }\end{array}$ & 200 & 151 & 63 \\
\hline 278 & $\begin{array}{l}\text { Purushottam } \\
\text { Nagar }\end{array}$ & $\begin{array}{l}\text { Purushottam } \\
\text { Nagar }\end{array}$ & 4 & NA & NA & NA & NA & NA \\
\hline 2621 & Law College & Law College & 1 & $\begin{array}{l}\text { Law College, Netaji Rd, Ellis Bridge, } \\
\text { Ahmedabad, Gujarat }\end{array}$ & Law College & 0 & $44 / 3$ & 45 \\
\hline 6412 & G Ward & Jivod & 0 & NA & NA & NA & NA & NA \\
\hline 6538 & $\begin{array}{l}\text { Sardar Patel } \\
\text { Chowk }\end{array}$ & NA & 252 & NA & NA & NA & NA & NA \\
\hline 6928 & $\begin{array}{l}\text { Janta Nagar } \\
\text { (Odhav) }\end{array}$ & NA & 1 & $\begin{array}{l}\text { Odhav, Janta Nagar, Odhav, } \\
\text { Ahmedabad, Gujarat }\end{array}$ & $\begin{array}{l}\text { Odhav } \\
\text { Approach }\end{array}$ & 400 & 143 & 77 \\
\hline 3454 & $\begin{array}{l}\text { Gandhi } \\
\text { Ashram }\end{array}$ & Gandhi Ashram & 1 & $\begin{array}{l}\text { Sabarmati Ashram, Ashram Rd, Old } \\
\text { Vadaj, Ahmedabad, Gujarat, } 380027\end{array}$ & $\begin{array}{l}\text { Gandhi } \\
\text { Ashram }\end{array}$ & 120 & 83 & 62 \\
\hline 7425 & Zanu Village & NA & 0 & NA & NA & NA & NA & NA \\
\hline
\end{tabular}

It was observed that the text-based search was able to locate only 50 percent of bus stop names searched in the sample dataset. The average distance of these place-tags from their respective nearest bus stop in Google Transit was observed to be $294.96 \mathrm{~m}$, with only 25 percent of stops being located within 100.0 meters of the place-tag. Moreover, only 27 percent of the place-tags were actually able to locate the desired bus stop. It was further observed that in nearly 82 percent of the searches, more than one place-tag was located, and most often these tags referred to locations in different localities than desired.

The route information retrieved from Google Transit for each pair of origin-destination stops in the sample was compared with the routes listed in AMTS timetable. As discussed above, of the 214 bus stops searched in Google Transit, only 107 could be located by a text-based search, and route from these stops to the Lal Darwaja Bus Terminus were determined by Google Transit's trip planner, which resulted in 54 distinct routes. In comparison with the AMTS route timetable, it was observed that only three routes had errors, and one route had temporarily been closed. It was further noticed that of the three routes, one route corresponded to the old timetable, which raises concerns about the maintenance of AMTS information on Google Transit. It is, therefore, desirable that transit websites provide information on the date of last updates.

In addition to Google Transit's trip planner, the ATMS website also provides useful information on public transport services, including a PDF file in the native language (Gujarati) containing the information on bus routes operated by AMTS. It also provides a text-based trip planner to search the route connecting a pair of origin and destination stops. The ATMS trip planner is far less effective as compared to Google Transit. The bus routes originating at the bus stops in the sample selected from the reference transport network and ending at the Lal Darwaja Bus Terminus were searched using the ATMS trip planner. 
It was observed that only 68 bus stops (32\%) could be located by name, and routes to the Lal Darwaja Bus Terminus for only 25 stops (12\%) could be retrieved in the sample of 214 bus stops. The information content of the AMTS website is, therefore, not adequate for pre-trip information.

\section{BRTS Information on the Internet}

Web-based PIS has been contemplated as a part of BRT system specifications. BRT, which was introduced in Ahmedabad in 2009, is being implemented in a phased manner. The system is, therefore, undergoing continuous changes that the website, maintained by AJL has to follow. As BRT currently operates on 10 routes with only 110 stops, the system is considerably smaller and, hence, less complex as compared to the AMTS route network.

The Ahmedabad BRT website provides information on stops, routes, fares, and schedules. BRT stops may be selected from a drop-down list, and bus lines passing through that stop are listed along with estimated arrival times of buses. While a map-based search is currently not available, the website provides Open Street Maps (OSM), which shows the location of BRT stops. Similarly, a bus line may be selected from the drop-down list and its corresponding timetable may be retrieved. Bus lines also can be plotted on OSM data. A fare calculator is available to compute fares between origin and destination stops. The website is still in the development stage, and much work needs to be done to make it more user-friendly and informative.

\section{Opportunities for PIS development in India}

With the introduction of BRT and the efforts towards overhauling public transport in several Indian cities gaining momentum in the past decade and with government programs such as the Jawaharlal Nehru National Urban Renewal Mission, etc., requirements for multimodal information have become a necessity for the public transport users. Websites have been recognized as a preferred medium for the dissemination of such information, as global experience reflects. The responsibility for public transport in Indian cities lies with the local government, although they are more often than not dependent upon central and state governments for funding and technical support. The multi-agency involvement in public transport calls for efforts to streamline data exchange and interoperability to fulfil the requirements of multimodal information systems.

The quality of data with regard to accuracy and updating is paramount to the success of any information system. The problems regarding data quality are further compounded by the multi-lingual population in India. Ahmedabad, for example, has Gujarati as its official State language and Hindi as its official National language, but English is the common language on the Internet. It was observed that several of the errors in the names of bus stops were due to the semantics of names. As government websites are not updated frequently, the problem is further aggravated. Transit agencies, which are already constrained by both financial and human resources, require cost-effective solutions with the lowest level of skill to ensure high-quality information content delivered over the Web. 


\section{Conclusion}

To combat the conventional "service for the poor" image, the National Urban Transport Policy (2006) emphasizes modernization of urban transport infrastructure, improved passenger information systems, and the use of intelligent transport systems for monitoring and control, apart from several other path-breaking recommendations. In the last decade, the introduction of BRT in several Indian cities has significantly altered the information needs of commuters, particularly for multimodal travel, as BRT in most Indian cities is operating in conjunction with regular bus services. In-terminal and on-board PIS have been deployed as part of BRT implementation, but Web-based multimodal information systems are yet to materialize. This paper reviewed the current state-of-the-practice in Web-based PIS in India and abroad and critically evaluated the existing sources of public transport information in Ahmedabad as a case study.

The printed transit timetables published by the public transport operators are not user-friendly, and their information content is incomplete. It was observed that only 40 percent of bus stops on a given route are listed in the transit timetables. Google Transit's trip planner is superior in terms of user-friendliness and information content when compared with the websites of public transport agencies and their printed transit timetables. The study, however, indicated that a map-based search of bus stops using Google Transit was able to locate only 62.8 percent of bus stops in a sample of 156 bus stops selected randomly from the reference public transport database of Ahmedabad. Moreover, a textbased search was able to identify only 50 percent of the stops. The study further observed that only 48 percent of the stop names have a similarity score greater than 95 percent on Jaro-Winkler similarity, and 33 percent have a Levenshtein distance above 95 percent, which implies that not only are conventional key-word based searches liable to fail, but also that significant effort will be necessary to rectify errors in the database.

Private sector initiatives such as Google Transit are continuously improving the quality of the user experience while setting high standards for service delivery. The issues pertaining to accuracy, coverage, and timeliness of the information in Google Transit highlights the necessity for proactive and continuous involvement of transit agencies in the development of Web-based PIS. Transit agencies in India need to adopt standards such as Google Transit Feed Specifications (GTFS) for transit data exchange across various stakeholders. The successful deployment of Transport Direct in the United Kingdom, which enables nationwide public transport information flows with the adoption of standards such as JourneyWeb, TransXChange, NaPTAN, and National Public Transport Gazetteer (DfT 2013), is an apt example for developing countries such as India to follow. While these standards have addressed the issues of syntactic heterogeneity, ontologies are increasingly being considered for attaining the semantic heterogeneity in information exchange (Billen et al. 2011). Service providers and technology providers will need to work in tandem to ensure the availability of high-quality data for dependable PIS for users of public transport in developing countries. 


\section{Acknowledgments}

The authors would like to thank Mr. A. S. Kiran Kumar, Director, Space Applications Centre, for the organizational support during the course of this study. We would also like to express our sincere gratitude to Dr. J. S. Parihar, Dr. Ajai, Dr. A. S. Rajawat, Mr. Saji Abraham, and Mr. Nilesh Desai for their valuable feedback.

\section{References}

Ahmedabad Municipal Corporation (AMC). 2013. http://www.ahmedabadbrts.com/, accessed January 2013.

Ahmedabad Municipal Transport Service (AMTS). 2013. http://www.amts.co.in/, accessed January 2013.

Bae, S. 1995. An Advanced Public Transportation Systems application: Feasibility study of bus passenger information systems operational test in the town of Blacksburg. Proc. Vehicle Navigation and Information Systems Conference. In conjunction with the Pacific Rim TransTech Conference. 6th International VNIS. A Ride into the Future, Jul 30-Aug 2, 1995: 408-413.

Balaji, D., S. Suresh, and P. Ganesh, P. 2003. Public transport information system for Chennai city using GIS-A pilot project. Proc. Map India 2003 Conference, New Delhi.

BayernInfo. 2013. http://www.bayerninfo.de/en, accessed January 2013.

Billen, R., J. Nogueras-Iso, F. J. López-Pellicer, and L. M. Vilches-Blázquez. 2011. Ontologies in the geographic information sector. In Falquet, G., C. Métral, J. Teller, and C. Tweed (eds.), Ontologies in Urban Development Projects. Springer, London.

Cain, A. 2007. Are printed transit materials a barrier to transit use? Journal of Public Transportation 10(2): 33-52.

Casey, R. F. 1999. Advanced Public Transportation Systems: The state of the art - Update 1999, Final report to the U.S. Department of Transportation, Federal Transit Administration. Report No. DOT-VNTSC-FTA-99-1, John A. Volpe National Transportation Systems Center, Cambridge, MA.

Casey, R. F. et al. 2000. Advanced Public Transportation Systems: The State of the Art Update 2000, Final Report to the U.S. Department of Transportation, Federal Transit Administration. Report No. DOT-VNTSC-FTA-99-5, John A. Volpe National Transportation Systems Center, Cambridge, MA.

Caulfield, B., and M. M. O'Mahony. 2007. An examination of the public transport information requirements of users. IEEE Transactions on Intelligent Transportation Systems 8(1): 21-30.

Cheng, Y.-H. 2011. Evaluating website service quality in public transport: Evidence from Taiwan High Speed Rail. Transportation Research Part C 19: 957-974.

Cherry, C., M. Hickman, and A. Garg. 2006. Design of a map-based transit itinerary planner. Journal of Public Transportation 9(2): 45-68. 
Department for Transport (DfT). 2013. http://www.dft.gov.uk/public-transportdatastandards/, accessed November 2013.

DIMTS. 2010. http://www.dimts.in/passengerinfo.html, accessed January 2010.

Eriksson, L., M. Friman, and A.-C. Norman. 2007. Electronic service quality: Public transport information on the Internet. Journal of Public Transportation 10(3): 35-46.

Farag, S., and G. Lyons. 2012. To use or not to use? An empirical study of pre-trip public transport information for business and leisure trips and comparison with car travel. Transport Policy 20: 82-92.

Google Maps. 2013. http://maps.google.co.in/maps, accessed January 2013.

Google Maps-Transit. 2013. http://www.google.co.in/intl/en/landing/transit/\#dmy, accessed January 2013.

Grotenhuis, J.-W., B. W. Wiegmans, and P. Rietveld. 2007. The desired quality of integrated multimodal travel information in public transport: Customer needs for time and effort savings. Transport Policy 14: 27-38.

Hiinnikainen, M., A. Laitinen, T. Hiimalainen, I. Kaisto, and K. Leskinen. 2001. Architecture of a passenger information system for public transport services. Proc. 54th Vehicular Technology Conference, IEEE VTS 2: 698-702.

Iles, R. 2005. Public Transport in Developing Countries. Elsevier Ltd., The Netherlands.

India Bus Route Mapping Project. 2013. http://busroutes.in/, accessed January 2013.

Infopolis 2 Consortium. 1998. Review of current passenger information systems. Commission of the European Communities - DG XIII.

Jung, S. W., K. H. Sung, T. W. Park, and H. C. Kwon. 2001. Intelligent integration of information on the Internet for travelers on demand. Proc. ISIE 2001, IEEE International Symposium on Industrial Electronics 1: 338-342.

Kasturia, S., and A. Verma. 2010. A multi-objective transit passenger information system design using GIS. ASCE Journal of Urban Planning and Development 136(1): 34-41.

King County. 2013. http://tripplanner.kingcounty.gov/, accessed January 2013.

MacDonald, M. et al. 2006. Intelligent Transport Systems in Europe-Opportunities for Future Research. World Scientific Publishing Co. Pvt. Ltd., Singapore.

Maher, A. 2008. Transport direct-Accessibility information, journey planning and its challenges. Proc. European Transport Conference, Association for European Transport, Netherlands, October 6-8, 2008.

MapUnity. 2010. http://www.btis.in/bus/, accessed January 2010.

Metropolitan Transportation Commission. 2013. http://tripplanner.transit.511.org/, accessed January 2013.

Ministry of Urban Development (MoUD). 2006. National Urban Transport Policy, Government of India, New Delhi. 
O' Flaherty, C. A. (ed.). 1997. Transport Planning and Traffic Engineering. Arnold, Great Britain.

Peng, Z. R., and R. Huang, 2000. Design and development of interactive trip planning for Web-based transit information systems. Transportation Research C: Emerging Technology 8: 409-425.

Peng, Z.-R., and E. Kim. 2008. A standard-based integration framework for distributed transit trip planning systems. Journal of Intelligent Transportation Systems 12(1): 13-28.

Radin S., D. Jackson, D. Rosner, and S. Peirce. 2002. Trip planning state of the practice. Report No. FTA-TRI-11-02.6. Federal Highway Administration, Washington, DC.

Reddy, D. 2002. Development of intelligent transport system in GIS environment. (M. Tech. dissertation), Indian Institute of Technology, Roorkee.

San Francisco Bay Area Rapid Transit District. 2013. http://www.bart.gov/, Accessed January, 2013.

Singh, V. 2007. Methodology for advanced traveler information system for developing countries. (M. Tech. dissertation), Indian Institute of Technology, Roorkee.

Tam, M. L., and W. H. K. Lam. 2005. Modeling the market penetration of personal public transport information system in Hong Kong. Journal of Intelligent Transportation Systems 9(2): 81-89.

Transport Direct. 2013. http://www.transportdirect.info, accessed January 2013.

Traveline Travel Services. 2010. http://www.traveline.com, accessed January 2010.

Transportation Research Board (TRB). 2003a. TCRP Synthesis 48: Real-time bus arrival information systems: A synthesis of transit practice. Transit Cooperative Research Program, Federal Transit Administration, TRB, Washington, DC.

TRB. 2003b. TCRP Report 92: Strategies for improved traveler information. TRB, Washington, DC.

Wang, J., and T. Kampke. 2006. The fastest itinerary in time-dependent decentralized travel information systems. Journal of Comb. Optim. 12: 167-185.

Watkins, K. E., B. Ferris, and G. S. Rutherford. 2010. Explore: An attraction search tool for transit trip planning. Journal of Public Transportation 13(4): 111-128.

Yoganand, N. 2004. Multimodal Advanced Traveler Information System for Delhi Metro. (M. Tech. dissertation), Indian Institute of Technology, Roorkee.

Zografos, K. G., and K. N. Androutsopoulos. 2008. Algorithms for itinerary planning in multimodal transportation networks. IEEE Transactions on Intelligent Transportation Systems 9(1): 175-182.

Zografos, K. G., K. N. Androutsopoulos, and V. Spitadakis. 2009. Design and assessment of an online passenger information system for integrated multimodal trip planning. IEEE Transactions on Intelligent Transportation Systems 10(2): 311-323. 


\section{About the Authors}

GAURAV V. JAIN (Gaurav.V.Jain@gmail.com, gvj@sac.isro.gov.in) is a Civil Engineering graduate with post-graduate studies in Urban and Regional Planning. He is a Scientist/ Engineer at the Space Applications Centre in the Geo-sciences Division and is pursuing doctoral research at the Indian Institute of Technology Roorkee. His research interests include applications of remote sensing and GIS in urban and regional planning.

DR. S. S. JAIN (profssjain@gmail.com) obtained his doctoral degree in Transportation Engineering from the Indian Institute of Technology Roorkee where he is Professor and Coordinator, Transportation Engineering Group, Department of Civil Engineering. He was founder of the Centre for Transportation Systems (CTRANS), IIT Roorkee. His research interests include transportation engineering, pavement management system, intelligent transportation system, road safety, and public transport planning and design.

Dr. Manoranjan Parida (mparida@gmail.com) holds a Ph.D. in Civil Engineering with post-graduate studies in Urban Planning. He is professor of Civil Engineering at the Indian Institute of Technology Roorkee and heads the Centre for Transportation Systems (CTRANS) at Roorkee. His research interests include urban transportation planning, transport environment interaction, and intelligent transportation systems. 